\title{
A new strategy for the synthesis of modified novolac resin and its polymer/clay nanocomposite
}

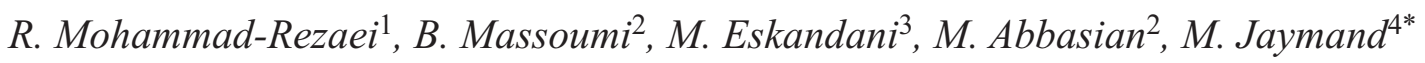 \\ ${ }^{1}$ Electrochemistry Research Laboratory, Faculty of Basic Sciences, Azarbaijan Shahid Madani University, Tabriz, Iran \\ ${ }^{2}$ Department of Chemistry, Payame Noor University, Tehran, Iran \\ ${ }^{3}$ Research Center for Pharmaceutical Nanotechnology, Tabriz University of Medical Sciences, Tabriz, Iran \\ ${ }^{4}$ Nano Drug Delivery Research Center, Kermanshah University of Medical Sciences, Kermanshah, Iran
}

Received 3 December 2018; accepted in revised form 28 January 2019

\begin{abstract}
A novel epoxy nanocomposite composed of epoxidized novolac (ENR), epoxidized polystyrene (EPSt), and nanoclay was fabricated and characterized successfully. For this purpose, the novolac was epoxylated using a substitution nucleophilic reaction between hydroxyl group of novolac and chlorine group of epichlorohydrin. The EPSt was synthesized through the oxidizing of an allylated PSt (All-PSt). A mixture of ENR (70 wt \%), EPSt (20 wt \%) and Cloisite ${ }^{\circledR} 20 \mathrm{~A}(5 \mathrm{wt} \%)$ was cured using ethylenediamine (EDA; $5 \mathrm{wt} \%$ ) to afford a C-ENR-EPSt/clay nanocomposite. The transition electron microscopy (TEM) as well as powder X-ray diffraction (XRD) analysis revealed that the fabricated nanocomposite has an exfoliated structure. As the thermal property studies results, the addition of EPSt as well as Cloisite ${ }^{\circledR} 20 \mathrm{~A}$ has synergistic effect on the thermal stability of the ENR resin.
\end{abstract}

Keywords: nanocomposites, epoxidized novolac, epoxidized polystyrene, clay, thermal stability

\section{Introduction}

Despite the long history of phenolic resins, these thermosetting polymers still attracted great deal of research efforts in both industrial as well as academic committees based on their superior features including good thermal stability, high strength, good chemical and corrosion resistances, electrical insulation, high stiffness, dimensional stability, high char yield, low shrinkage after curing, as well as low production cost [1-4]. They have various applications such as electronic and thermal insulation materials, molding compounds, adhesive, foundry, coatings, and composite materials. In general, phenolic resins are divided into resole and novolac types depending on the stoichiometric ratio of phenol to formaldehyde as well as the $\mathrm{pH}$ value of the reaction [4-8].

The most important drawbacks of traditional phenolic resins that limited their application range are inherent brittleness, high shaping pressure, and dark color due to easy oxidation of phenolic groups. Some strategies, including blending with elastomers, thermoplastic polymers, incorporation of nanofillers (e.g., silica nanoparticles and carbon nanotubes) or fibers (e.g., glass), and incorporation of flexible chains into the polymer network are suggested to circumvent of above-mentioned problems $[5,7,9,10]$.

Another efficient strategy is epoxylation, especially in the case of novolac type phenolic resins, known as epoxidized novolac resin (ENR), which led to voidfree thermosets after curing $[11,12]$. The co-curing of ENR with epoxylated thermoplastic polymers (e.g., polystyrene) synthesized with well-defined structure can be considered as versatile and synergic strategy. In this context, reversible deactivation radical polymerization (RDRP; otherwise known as controlled or 'living' radical polymerization) has been developed 
as efficient strategy for synthesize polymeric materials with well-defined structure as well as relatively low dispersities [13-16].

In general, RDRP is divided into three main categories including, nitroxide-mediated polymerization (NMP) $[16,17]$, atom transfer radical polymerization (ATRP) [14, 18], and reversible addition-fragmentation chain transfer (RAFT) polymerization $[13,19]$. Among these, NMP approach is the first and easiest technology. This technique is more interesting due to its applicability to a wider range of monomers (e.g., acrylamides, acrylates, and vinyl chloride), synthesis of copolymers with controlled molecular weight and well-defined architecture (e.g., block, star, and graft) under relatively mild conditions, as well as simple and feasible activation-deactivation equilibrium only by increasing of temperature for polymerization and cooling for quenching of reaction $[17,20]$.

On the other hand, more modification of the physicochemical characteristics of phenolic resins can be achieved using incorporation of nanofillers as mentioned above. In this context, phenolic resins/clay nanocomposites have been received a great deal of interest mainly due to superior properties of the resultant nanohybrid in comparison with pristine polymers [20, 21]. It is well accepted that polymer/clay nanocomposites exhibits enhanced corrosion resistance, fire retardance, gas barrier protperties, and ionic conductiviy; increased thermal stability and mechanical strength; and decreased absorption of organic liquids [16, 22, 23].

According to above-mentioned facts, the aim of this study was the design and application of a new strategy for the fabrication of a modified novolac resin (NR) as follows. Firstly, NR was epoxylated through the functionalization with epichlorohydrin in super basic medium. In second step, a poly(styrene-co-4chloromethyl styrene) $[\mathrm{P}(\mathrm{St}-\mathrm{co}-\mathrm{CMSt})]$ was synthesized using nitroxide-mediated polymerization (NMP) technique, and then allylated through a substitution nucleophilic reaction between the deprotonated allyl alcohol and chlorine groups. Afterwards the allyl groups were oxidized into epoxide groups with meta-chloroperoxybenzoic acid ( $m$-CPBA) in order to afford epoxylated PSt (EPSt). A small amount of modified clay (5 wt $\%$; Cloisite ${ }^{\circledR} 20 \mathrm{~A}$ ) was added to the mixture of ENR (70 wt \%) and EPSt (20 wt \%), and then cured using ethylenediamine $(5 \mathrm{wt} \%)$ to produce a C-ENR-EPSt/clay nanocomposite.

\section{Experimental}

\subsection{Materials}

2,2,6,6-Tetramethyl-1-piperidinyloxy (TEMPO) was synthesized in our laboratory [20,24]. Styrene and 4-chloromethyl styrene monomers were purchased from Merck (Darmstadt, Germany) and distilled under reduced pressure before use. Cloisite ${ }^{\circledR} 20 \mathrm{~A}$ was supplied from Southern Clay Products, Inc. (Gonzales, TX, USA) and was used as received. Novolac resin (SPS-401) was supplied from Resitan (Qazvin, Iran) and was used as received. Epichlorohydrin $(\mathrm{ECH}$; Merck) was dried by calcium hydride $\left(\mathrm{CaH}_{2}\right)$, and distilled twice under reduced pressure before use. Tetrahydrofuran (THF) was purchased from Merck, dried by refluxing over sodium, and distilled under argon prior to use. Tetrabutyl ammonium iodide, sodium hydride $(\mathrm{NaH})$, sodium hydroxide $(\mathrm{NaOH})$, benzyl peroxide (BPO), allyl alcohol, meta-chloroperoxybenzoic acid ( $m$-CPBA), anhydrous sodium sulfate $\left(\mathrm{Na}_{2} \mathrm{SO}_{4}\right)$, and ethylenediamine (EDA) were purchased from Sigma-Aldrich (St. Louis, MO, USA) and were used as received. All other reagents were purchased from Merck or Sigma-Aldrich and purified according to the standard methods.

\subsection{Synthesis of $\mathrm{P}(\mathrm{St}-\mathrm{co}-\mathrm{CMSt})$ via $\mathrm{NMP}$ technique}

A flame-dried polymerization ampoule was charged with styrene $(0.92 \mathrm{ml}, 8 \mathrm{mmol})$, 4-chloromethyl styrene $(1.40 \mathrm{ml}, 10.2 \mathrm{mmol}), \quad$ BPO $(0.05 \mathrm{~g}$, $0.20 \mathrm{mmol})$, and TEMPO $(0.05 \mathrm{~g}, 0.30 \mathrm{mmol})$. The ampoule was degassed with several freeze-pumpthaw cycles, sealed off under vacuum and placed in an oil bath at $95^{\circ} \mathrm{C}$ for about 4 hours. Afterward, the temperature was allowed to increase to $130^{\circ} \mathrm{C}$, and the reaction mixture was shacked for another 12 hours. At the end of this time, the crude product was cooled, diluted with THF $(10 \mathrm{ml})$ and precipitated into excess methanol. The product was filtered, washed with methanol several times, and dried in vacuum at room temperature.

\subsection{Synthesis of allylated-polystyrene (All-PSt)}

The All-PSt was synthesized through a substitution nucleophilic reaction as follows. For this purpose, a $50 \mathrm{ml}$ three-neck round-bottom glass reactor equipped with a condenser, gas inlet/outlet, and a magnetic stirrer, was charged with allyl alcohol (1 m, $15 \mathrm{mmol})$, 
and dried $N, N$-dimethylformamide (DMF, $20 \mathrm{ml}$ ). The content of the reactor was de-aerated by bubbling highly pure argon gas for some minutes, and then, hexane-washed $\mathrm{NaH}$ (from $60 \%$ suspension in oil; $0.46 \mathrm{~g}, 18 \mathrm{mmol}$ ) was added to the flask. The reaction mixture was stirred for about 1 hour under argon protection.
In a separate container, dried $\mathrm{P}(\mathrm{St}-\mathrm{co}-\mathrm{CMSt})(2.50 \mathrm{~g})$ was dissolved in dried DMF $(20 \mathrm{ml})$. This solution was de-aerated by bubbling highly pure argon gas for 15 minutes, and then added to the above-mentioned reactor under argon protection. The reaction mixture was stirred for about 6 hours at $50^{\circ} \mathrm{C}$, and then the synthesized All-PSt was separated by precipitation<smiles>C=Cc1ccc(CCl)c[cH+]c1</smiles><smiles>CC1(C)CCCC(C)(C)N1OC(CCl)CC(CC(CC(CC(CC(OC(=O)c1ccccc1)c1ccccc1)c1ccccc1)c1ccccc1)c1ccccc1)c1ccccc1</smiles>

$\mathrm{P}(\mathrm{St}-\mathrm{co}-\mathrm{CMSt})$

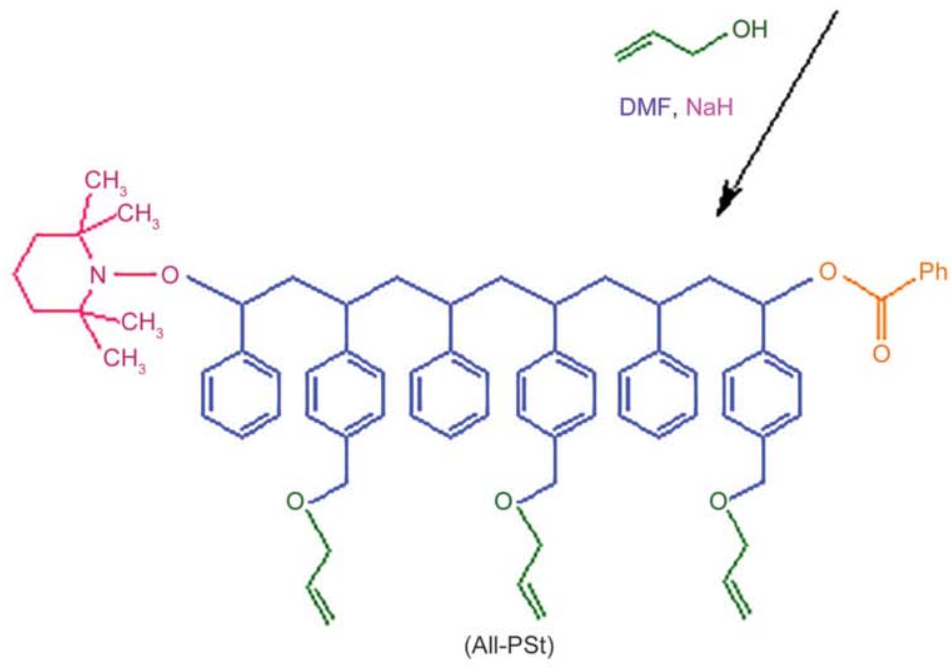<smiles>CC1(C)CCCC(C)(C)N1OC(CC(CC(CC(CC(CC(CC(c1ccccc1)c1ccccc1)c1ccc(COCC2CO2)cc1)c1ccccc1)c1ccc(COCC2CO2)cc1)c1ccccc1)c1cccc(COCC2CO2)c1)OC(=O)c1ccccc1</smiles>

Figure 1. The overall strategy for the synthesis of EPSt. 
in excess cold methanol. The product was filtered, washed several times with methanol, and dried in vacuum at room temperature.

\subsection{Synthesis of EPSt}

The EPSt was synthesized through the oxidation of allyl groups using excess $m$-CPBA. For this purpose, a $100 \mathrm{ml}$ round-bottom flask equipped with a condenser, and a magnetic stirrer, was charged with the synthesized All-PSt $(2.00 \mathrm{~g}), m$-CPBA $(0.50 \mathrm{~g}$, $3 \mathrm{mmol})$, and $\mathrm{CH}_{2} \mathrm{Cl}_{2}(70 \mathrm{ml})$. The reaction mixture was stirred for about 6 hours at room temperature. At the end of this time, the product was precipitated into a large amount of methanol; washed sequentially with aqueous sodium bicarbonate (5 wt\%), and methanol several times; and finally dried in vacuum at room temperature (Figure 1).

\subsection{Synthesis of ENR}

A $50 \mathrm{ml}$ three-neck round-bottom glass reactor equipped with a condenser, a dropping funnel, and a magnetic stirrer was charged with dried NR $(4.00 \mathrm{~g})$, ECH $(17.3 \mathrm{ml}, 3 \mathrm{~mol})$, and tetrabutyl ammonium iodide $(0.10 \mathrm{~g}, 0.27 \mathrm{mmol})$ as phase transfer catalyst. The flask was warmed to $100^{\circ} \mathrm{C}$ for about 3 hours with stirring, and then cooled to $60^{\circ} \mathrm{C}$ followed by the addition an aqueous solution of $\mathrm{NaOH}(10 \% \mathrm{w} / \mathrm{v}$, $15 \mathrm{ml}$ ) through dropping funnel. Afterward, the reaction was continued for another 2 hours at $60^{\circ} \mathrm{C}$. At this time, the flask was cooled to room temperature, chloroform $(30 \mathrm{ml})$ was added and extracted with

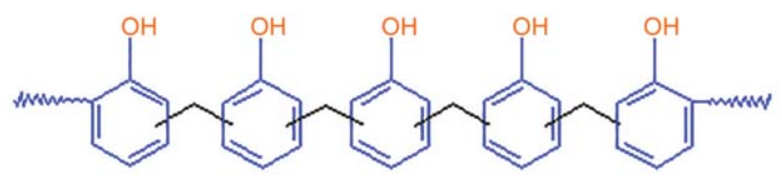

(NR)
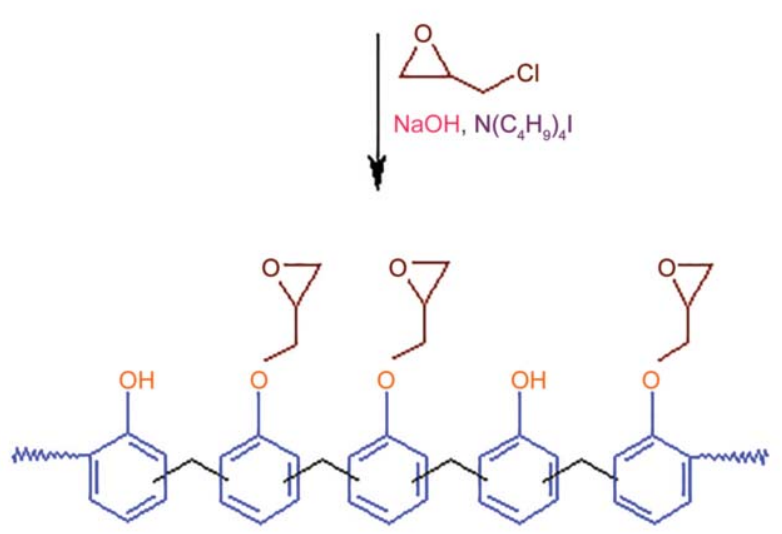

(ENR)

Figure 2. Synthesis of ENR. deionized water several times to remove the generated salts as well as unreacted reagents. The organic layer was dried over anhydrous $\mathrm{Na}_{2} \mathrm{SO}_{4}$ and the solvent (chloroform) was removed using a rotary evaporator (Figure 2).

\subsection{Fabrication of nanocomposite}

The C-ENR-EPSt/clay nanocomposite was synthesized through the curing a mixture of ENR ( $70 \mathrm{wt} \%)$, EPSt (20 wt \%), and Cloisite ${ }^{\circledR} 20 \mathrm{~A}$ (5 wt \%) using EDA $(5 \mathrm{wt} \%)$ as follows. In a typical experiment, ENR, EPSt, and Cloisite ${ }^{\circledR} 20 \mathrm{~A}$ were dissolved in dried THF, sonicated for about 15 minutes, and then stirred for 3 hours. Afterward, temperature was increased to $80^{\circ} \mathrm{C}$ at a rate of $3^{\circ} \mathrm{C} \cdot \mathrm{min}^{-1}$ and remained at this temperature for 2 hours. Temperature was held at $120^{\circ} \mathrm{C}$ for 4 hours, and subsequently at $180^{\circ} \mathrm{C}$ for 3 hours in order to achieve post-cure. The C-ENR and C-ENR-EPSt were fabricated by the same approach without the addition of Cloisite ${ }^{\circledR} 20 \mathrm{~A}$.

\subsection{Characterization}

Fourier transform infrared (FTIR) spectroscopy was performed using a Shimadzu 8101M FTIR (Kyoto, Japan) at room temperature. The samples were prepared in the pellet form with potassium bromide $(\mathrm{KBr})$ powder. The spectra were measured at a wave number resolution of $4 \mathrm{~cm}^{-1}$ as single scan for a spectral range from 400 to $4000 \mathrm{~cm}^{-1}$. Proton nuclear magnetic resonance $\left({ }^{1} \mathrm{H}\right.$ NMR $)$ spectra were recorded on an FT-NMR Bruker spectrometer (Bruker, Ettlingen, Germany) with an operating frequency of $400 \mathrm{MHz}$ at $25^{\circ} \mathrm{C}$. The sample for NMR spectroscopy was prepared by dissolving about $10 \mathrm{mg}$ of sample in $1 \mathrm{ml}$ of deuterated chloroform $\left(\mathrm{CDCl}_{3}\right)$ as solvent, and chemical shifts were given in ppm units using tetramethylsilane (TMS) as an internal reference. The molecular weight of the synthesized $\mathrm{P}(\mathrm{St}-\mathrm{co}-\mathrm{CMSt})$ was determined by gel permeation chromatography (GPC) analysis with a Maxima 820 GPC Analysis Report (Ventura, CA, USA), using polystyrene $\left(M_{\mathrm{n}}=\right.$ 189300, 59950, 30150, 9910, 3760, 1660, and $650 \mathrm{~g} \cdot \mathrm{mol}^{-1}$ ) calibration standards. Tetrahydrofuran (THF) was used as eluent at a flow rate of $1 \mathrm{ml} \cdot \mathrm{min}^{-1}$ and column temperature of $25^{\circ} \mathrm{C}$. Differential scanning calorimetric (DSC) analyses were carried out using an NETZSCH (Selb, Bavaria, Germany), DSC $200 \mathrm{~F} 3$ Maia with a heating rate of $10^{\circ} \mathrm{C} \cdot \mathrm{min}^{-1}$. Thermal properties of the synthesized samples were examined using thermogravimetric analyzer (TGA-PL 
STA 1640 equipment (Polymer Laboratories, Shropshire, UK)). The thermogravimetric analysis (TGA) experiment was conducted under a nitrogen atmosphere from room temperature to $700^{\circ} \mathrm{C}$ with a heating rate of $10^{\circ} \mathrm{C} \cdot \mathrm{min}^{-1}$. Transmission electron microscopy (TEM) was conducted on a Philips CM10-TH microscope (Phillips, Eindhoven, The Netherlands) at an accelerating voltage of $100 \mathrm{kV}$. The powder X-ray diffraction (XRD) analysis were performed on a Siemens D5000 diffractometer (Aubrey, Texas, USA), $\mathrm{X}$-ray generator $(\mathrm{CuK} \alpha$ radiation with $\lambda=1.5406 \AA)$ in the scan range from 2 to $20^{\circ}(2 \theta)$ at room temperature.

\section{Results and discussion}

\subsection{Characterization of EPSt}

It is well established that NMP allows the synthesis of polymeric materials with narrow molecular weight distribution as evidenced by a dispersity approaching 1. For approving this theory, the synthesized $\mathrm{P}$ (St-co-CMSt) copolymer was analyzed using GPC as shown in Figure 3. The GPC results revealed that the $\mathrm{P}(\mathrm{St}-\mathrm{co}-\mathrm{CMSt})$ was synthesized with molecular weight of $13700 \mathrm{~g} \cdot \mathrm{mol}^{-1}$, and dispersity of 1.17 . These results confirm the controlled copolymerization of styrene and 4-chloromethyl styrene monomers using TEMPO.

The synthesized EPSt was characterized using FTIR and ${ }^{1} \mathrm{H}$ NMR spectroscopies as shown in Figures 4 and 5. The most important absorption bands of $\mathrm{P}(\mathrm{St}-$ co-CMSt) copolymer are the stretching vibration of aliphatic and aromatic $\mathrm{C}-\mathrm{H}$ at $3100-2800 \mathrm{~cm}^{-1}$ region, weak aromatic overtone and combination bands in the $2100-1650 \mathrm{~cm}^{-1}$ region, the aromatic $\mathrm{C}=\mathrm{C}$ stretching vibrations at 1608 and $1487 \mathrm{~cm}^{-1}$, $-\mathrm{CH}_{2}$ bending vibrations at 1442 and $1373 \mathrm{~cm}^{-1}$, and $\gamma(\mathrm{C}-\mathrm{H})$ in the aromatic ring at 825 and $756 \mathrm{~cm}^{-1}$.

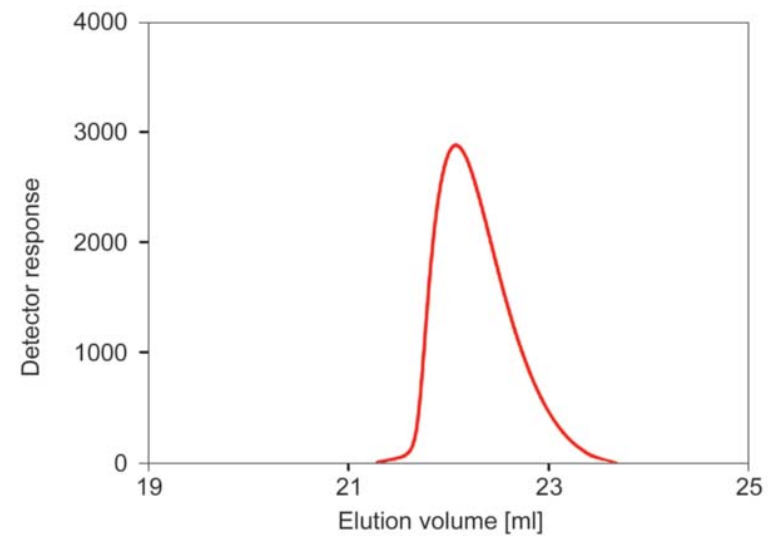

Figure 3. GPC chromatogram of $\mathrm{P}(\mathrm{St}-\mathrm{co}-\mathrm{CMSt})$ copolymer.

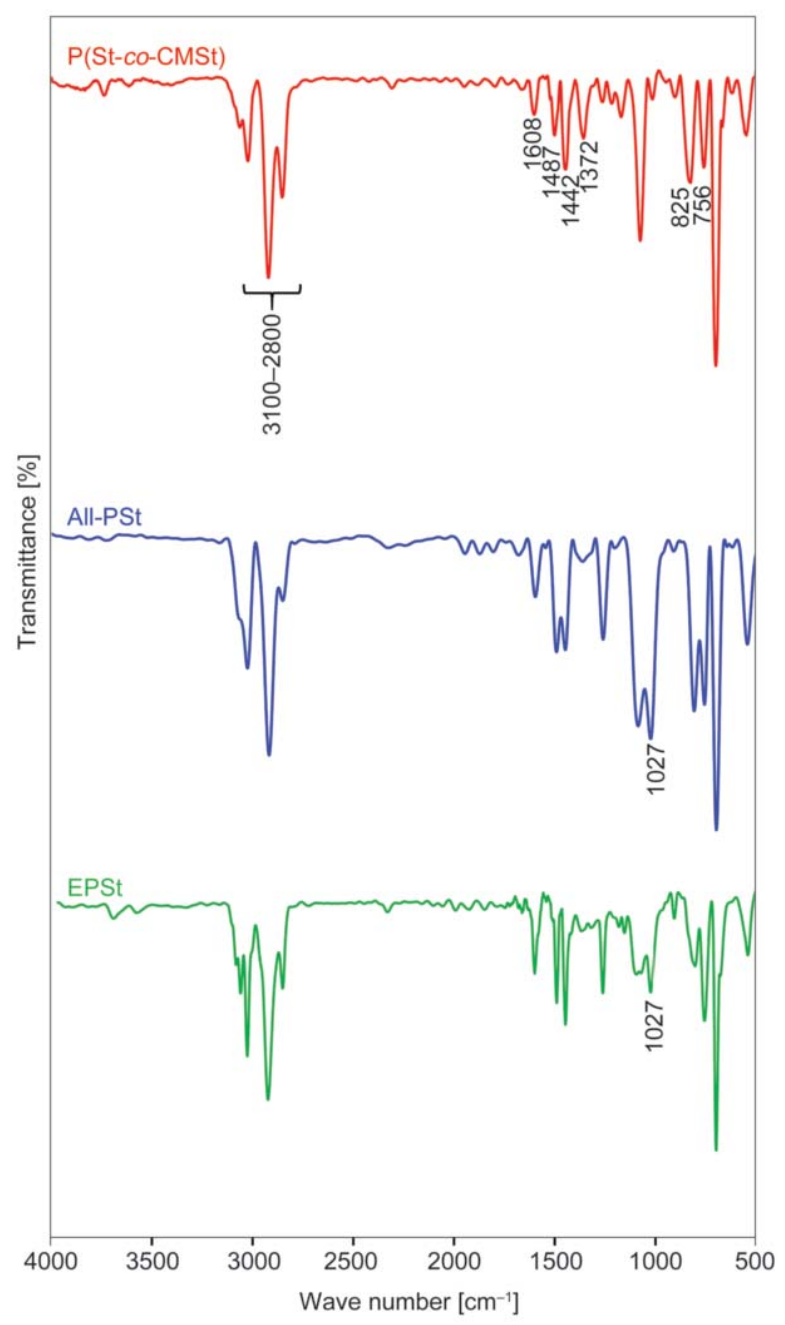

Figure 4. FTIR spectra of $\mathrm{P}(\mathrm{St}-\mathrm{co}$-CMSt) copolymer, AllPSt, and EPSt.

The most important change in the FTIR spectrum of the All-PSt is the appearance of a new absorption band at $1027 \mathrm{~cm}^{-1}$ that corresponded to the $\mathrm{C}-\mathrm{O}$ stretching vibration. The absorption band of aliphatic $\mathrm{C}=\mathrm{C}$ related to allyl group was overlapped with the aromatic carbon-carbon double band of phenyl rings. As seen the FTIR spectrum of the EPSt showed similar absorption band due to overlapping (Figure 4).

All above-mentioned samples were further characterized using ${ }^{1} \mathrm{H}$ NMR spectroscopy as shown in Figure 5. The ${ }^{1} \mathrm{H}$ NMR spectrum of $\mathrm{P}(\mathrm{St}-\mathrm{co}-\mathrm{CMSt})$ copolymer exhibited chemical shifts at 1.30-2.20 related to the methine and methylene protons of polystyrene backbone $(\mathrm{a}, \mathrm{b})$. The chemical resonance of $-\mathrm{CH}_{2} \mathrm{Cl}$ group at $4.30-4.60 \mathrm{ppm}$ (c), and the chemical shifts of aromatic protons at $6.40-7.20 \mathrm{ppm}$ (d) are other characteristic peaks of $\mathrm{P}(\mathrm{St}-\mathrm{co}$-CMSt) copolymer. In addition, the molar compositions of styrene and 4-chloromethyl styrene in the synthesized 

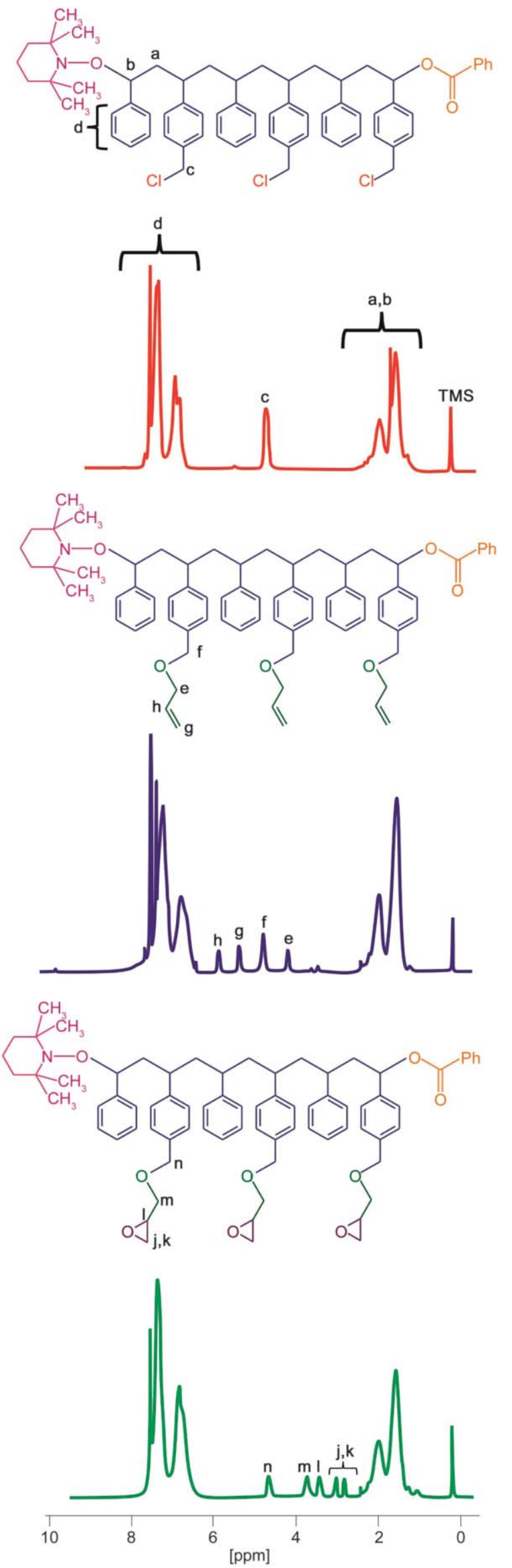

Figure 5. ${ }^{1} \mathrm{H}$ NMR spectra of $\mathrm{P}(\mathrm{St}-\mathrm{co}-\mathrm{CMSt})$ copolymer, All-PSt, and EPSt. copolymer were calculated to be 52 and $48 \%$, respectively from the ${ }^{1} \mathrm{H}$ NMR data [20].

The ${ }^{1} \mathrm{H}$ NMR spectrum of the All-PSt exhibited the chemical shifts of allylic $-\mathrm{CH}$ and $-\mathrm{CH}_{2}$ protons at $5.90(\mathrm{~h})$ and $5.35 \mathrm{ppm}(\mathrm{g})$, respectively, the chemical resonance of $-\mathrm{OCH}_{2}$ protons that adjusted with phenyl ring at $4.55 \mathrm{ppm}(\mathrm{f})$, and the chemical resonance of $-\mathrm{OCH}_{2}$ protons that adjusted with vinyl group at $4.15 \mathrm{ppm}$ (e). These chemical shifts revealed the successful incorporation of allyl groups into the PSt backbone. In addition, the chemical resonance of $-\mathrm{CH}_{2} \mathrm{Cl}$ group is disappeared that revealed the complete conversion of chlorine groups to the allyl groups.

The oxidation of allyl group into the epoxide groups was confirmed through the disappearance of allylic $-\mathrm{CH}$ and $-\mathrm{CH}_{2}$ protons at 5.90 and $5.35 \mathrm{ppm}$ as well as appearance of epoxide ring protons as labeled in the ${ }^{1} \mathrm{H}$ NMR spectrum of EPSt.

\subsection{Characterization of ENR}

The FTIR spectrum of the NR exhibited the characteristic absorption bands of the stretching vibrations of aliphatic and aromatic $\mathrm{C}-\mathrm{H}$ at $3020-2850 \mathrm{~cm}^{-1}$ region, the bending vibrations of $\mathrm{C}-\mathrm{H}$ at 1442 and $1351 \mathrm{~cm}^{-1}$, the stretching vibrations of aromatic $\mathrm{C}=\mathrm{C}$ at 1602 and $1503 \mathrm{~cm}^{-1}$, the stretching vibration of $\mathrm{C}-\mathrm{O}$ at $1226 \mathrm{~cm}^{-1}$, and the characteristic of orthoand para-substituted phenolic groups at 823 and $762 \mathrm{~cm}^{-1}$. Furthermore, the stretching vibration of hydroxyl group appeared as a broad and strong band at about $3400 \mathrm{~cm}^{-1}$.

After epoxylation of NR the absorption bands at 1012 and $926 \mathrm{~cm}^{-1}$ related to asymmetric and symmetric epoxide ring deformation bands, respectively are the most important changes in the FTIR spectrum of the ENR. In addition, the stretching vibration of hydroxyl group at 3400 is decreased significantly, while the stretching vibrations of $\mathrm{C}-\mathrm{H}$ (especially aliphatic $\mathrm{C}-\mathrm{H}$ ) is increased due to conversion of the most numbers of the hydroxyl groups into epoxide groups (Figure 6).

The ENR was further characterized using ${ }^{1} \mathrm{H}$ NMR spectroscopy as illustrated in Figure 7. As seen, the ${ }^{1} \mathrm{H}$ NMR spectrum of the NR exhibited chemical shift of aliphatic $-\mathrm{CH}_{2}$ bridge at $3.20-3.80 \mathrm{ppm}$ (a), the chemical shifts of aromatic protons corresponding to the phenyl ring at 6.90-7.10 ppm (b), and the chemical shift of hydroxyl group at 7.90-8.10 ppm (c). 


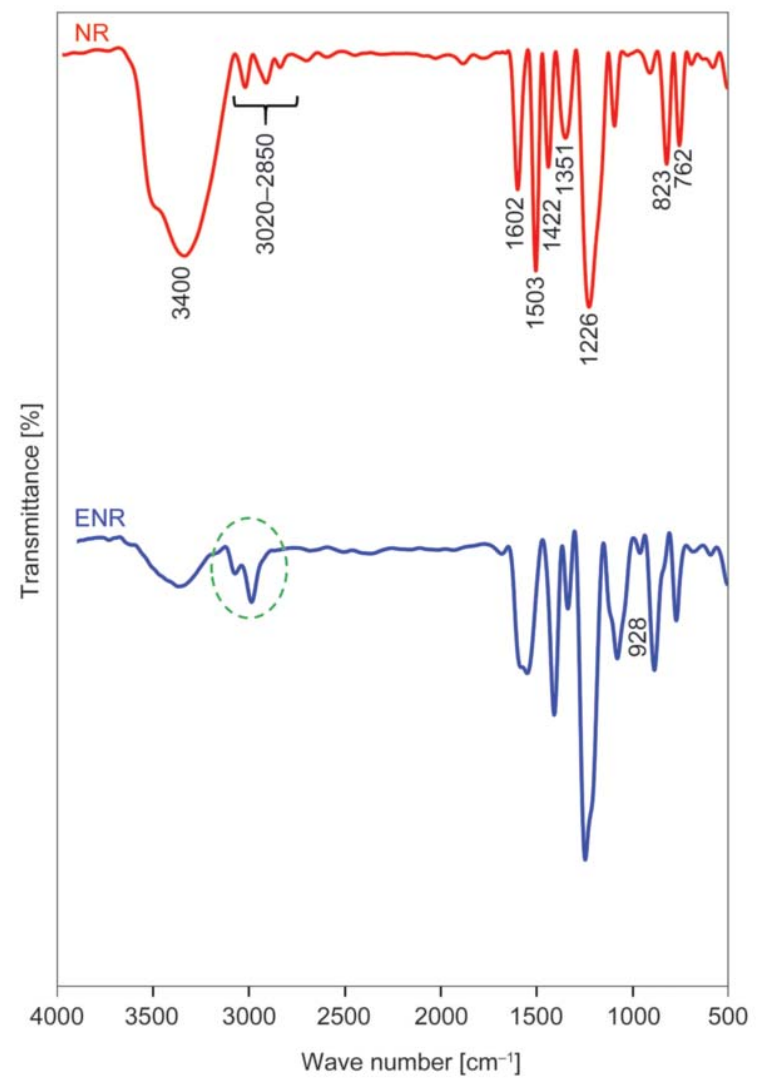

Figure 6. FTIR spectra of NR and ENR.

After epoxylation of NR, the most important changes in the ${ }^{1} \mathrm{H}$ NMR spectrum are the chemical resonances of glycidyl group (d, e, and f) and methylene
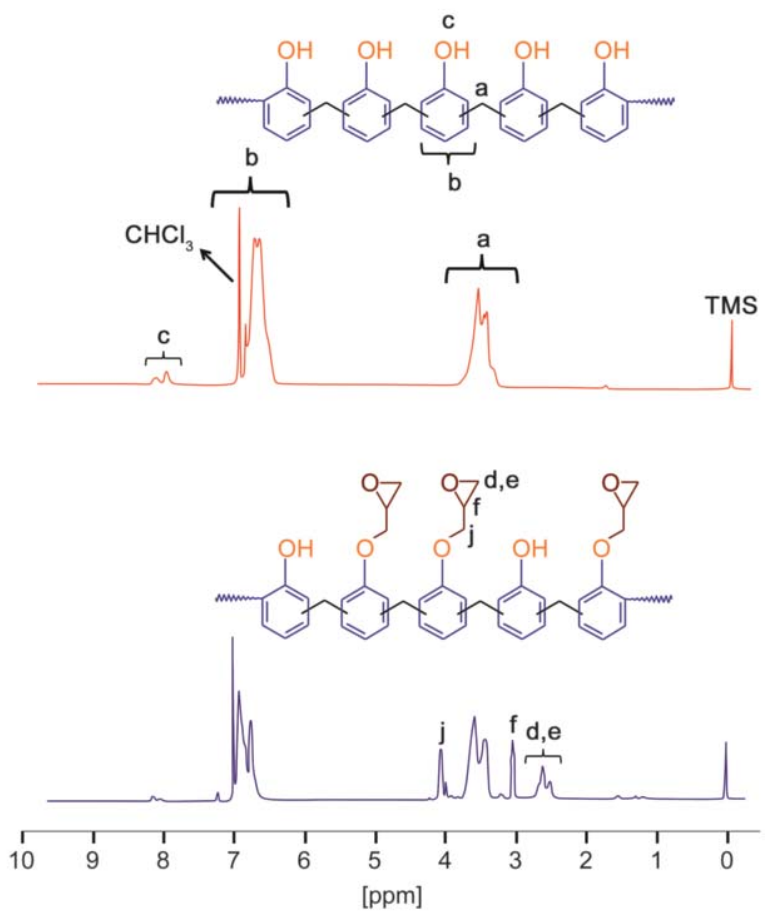

Figure 7. ${ }^{1} \mathrm{H}$ NMR spectra of NR and ENR. bridge (j) as labeled in the spectrum. Furthermore, the chemical resonance of hydroxyl group is decreased significantly that revealed most of the hydroxyl groups are converted to epoxy groups (Figure 7).

\subsection{Characterization of nanocomposite}

\subsubsection{Structure and morphology investigation}

The C-ENR-EPSt/Cloisite ${ }^{\circledR} 20$ A nanocomposite was fabricated through a solution intercalation approach followed by curing the mixture using EDA. The fabricated nanocomposite was characterized using XRD, TEM, and TGA as follows.

The structure of a polymer/clay hybrid is very important parameter that influences the physicochemical features of the final (nano-)composite. In general, $\mathrm{XRD}$ is the most common equipment that applied to investigate the structure types of the polymer/clay nanocomposites that is, intercalated and/or exfoliated structures, because the peaks change with the gallery height of the clay. An intercalated structure was characterized through a decrease in $2 \theta$, which would indicate an increase in the interlayer spacing. In contrast, the formation of an exfoliated structure usually lead to complete loss of registry between the silicate layers, and thus no peak can be seen in the XRD trace. However, in some cases a disordered immiscible system is obtained, which also shows no diffraction peak(s) in XRD pattern; hence, the absence of an XRD peak cannot be taken as definitive evidence of the formation of an exfoliated nanocomposite [20]. In these cases, usually TEM image is require for obtain further evidence.

As seen in Figure 8a, Cloisite ${ }^{\circledR}$ 20A exhibited a diffraction peak at $3.68^{\circ}$. In contrast, the C-ENR-EPSt/ Cloisite ${ }^{\circledR} 20 \mathrm{~A}$ nanocomposite has no diffraction peak in XRD pattern. Thus, according to above discussion, it could be an immiscible or exfoliated structure was obtained for the fabricated C-ENR-EPSt/ Cloisite $^{\circledR}$ 20A nanocomposite.

Additional evidence on the structure of the fabricated nanocomposite was also obtained using TEM as illustrated in Figure 8b. In this image light regions represent the polymer matrix (ENR and EPSt), and dark lines indicate clay layers. As seen, Cloisite ${ }^{\circledR} 20 \mathrm{~A}$ randomly dispersed in the C-ENR-EPSt matrix; however, a small number of clay layered stacks. TEM image provided evidence for the formation of an exfoliated structure for the fabricated nanocomposite, in accordance with XRD pattern. 

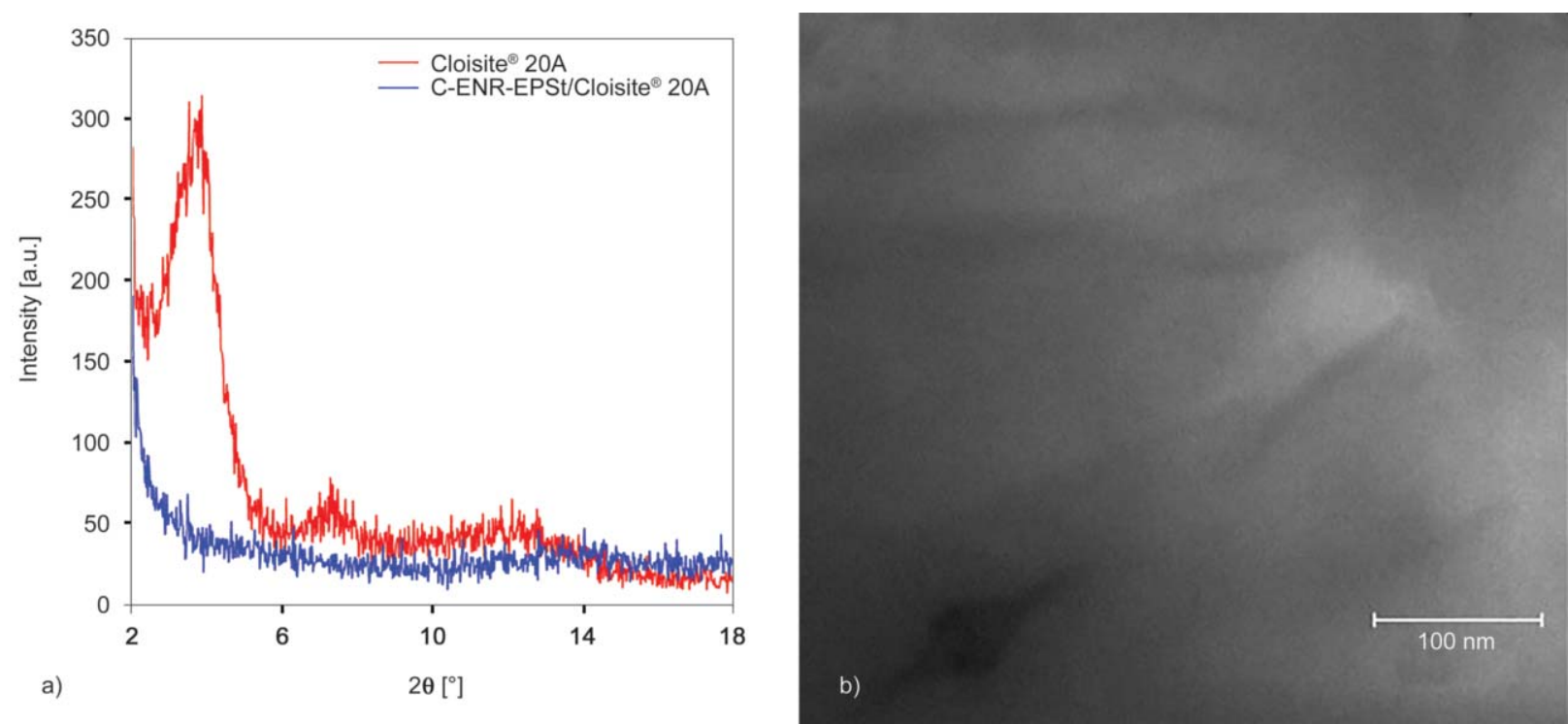

Figure 8. XRD patterns of Cloisite ${ }^{\circledR} 20 \mathrm{~A}$, and C-ENR-EPSt/Cloisite ${ }^{\circledR} 20 \mathrm{~A}$ nanocomposite (a), and TEM image of C-ENREPSt/Cloisite ${ }^{\circledR} 20 \mathrm{~A}$ nanocomposite (b).

\subsubsection{Thermal property study}

The thermal degradation of C-ENR, P(St-co-CMSt), C-ENR-EPSt, and C-ENR-EPSt/Cloisite ${ }^{\circledR} 20$ A nanocomposite upon heating under nitrogen atmosphere were studied using TGA as shown in Figure 9. As seen, the cured-ENR (C-ENR) degraded in a two-step processes. The first step at 200 to $300^{\circ} \mathrm{C}(17 \mathrm{wt} \%)$ is corresponded to the structural changes in the novolac resin network. Some portion of this weight loss can be originated form degradation of small molecules. After $300^{\circ} \mathrm{C}$, the rate of degradation is rapidly increased. This weight loss process (300 to $430{ }^{\circ} \mathrm{C}, 41 \mathrm{wt} \%$ ) is related to methylene bridges decomposition into methyl, phenol, and cresol groups. Degradation of phenol units may have occurred in the next stage. The residue at $600^{\circ} \mathrm{C}$ for this sample

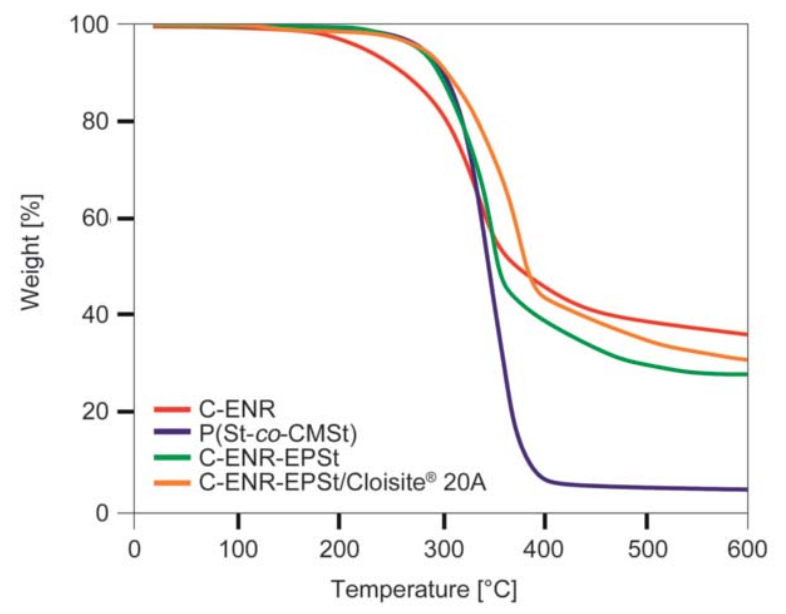

Figure 9. TGA curves of C-ENR, $\mathrm{P}(\mathrm{St}-\mathrm{co}$-CMSt), C-ENREPSt, and C-ENR-EPSt/Cloisite ${ }^{\circledR} 20 \mathrm{~A}$ nanocomposite. is about $37 \mathrm{wt} \%$. It is evident that the major degradation of $\mathrm{P}(\mathrm{St}-\mathrm{co}-\mathrm{CMSt})$ copolymer was occurring in one step at around 290 to $400^{\circ} \mathrm{C}$, and after which the loss rate slows down. The residue at $600{ }^{\circ} \mathrm{C}$ for $\mathrm{P}(\mathrm{St}-\mathrm{co}-\mathrm{CMSt})$ copolymer is $4 \mathrm{wt} \%$.

The characteristic TGA curve of C-ENR-EPSt exhibited a three-step weight loss process. The first step at 220 to $280^{\circ} \mathrm{C}(5 \mathrm{wt} \%)$ is related to the structural changes in the novolac resin. The second step at 290 to $380^{\circ} \mathrm{C},(50 \mathrm{wt} \%)$ is associated with the methylene bridges decomposition into methyl, phenol, and cresol groups. The final degradation step at 380 to $500{ }^{\circ} \mathrm{C}(19 \mathrm{wt} \%)$ is associated with PSt chains scission as well as degradation of generated phenol units. After which the loss rate slows down, and the residue at $600{ }^{\circ} \mathrm{C}$ for this sample is about $27 \mathrm{wt} \%$.

The TGA curve of C-ENR-EPSt/Cloisite ${ }^{\circledR} 20$ A nanocomposite exhibited similar degradation process as mentioned above. It should be pointed out that the weight loss at 120 to $200{ }^{\circ} \mathrm{C}(2 \mathrm{wt} \%)$ is related to the dehydration of clay as well as degradation of hydrogenated tallow that used to modification of clay. The nanocomposite finally reach to char residue of $31 \mathrm{wt} \%$ at the end of experiment. In addition, due to strong interactions (e.g., hydrogen bonding) between the functional groups of polymeric chains and clay the fabricated nanocomposite exhibited higher thermal stability than those of the neat C-ENR-EPSt. At the end of this section, it is worth noting that the addition of EPSt as well as clay has synergistic effect on the thermal stability of the ENR resin. 


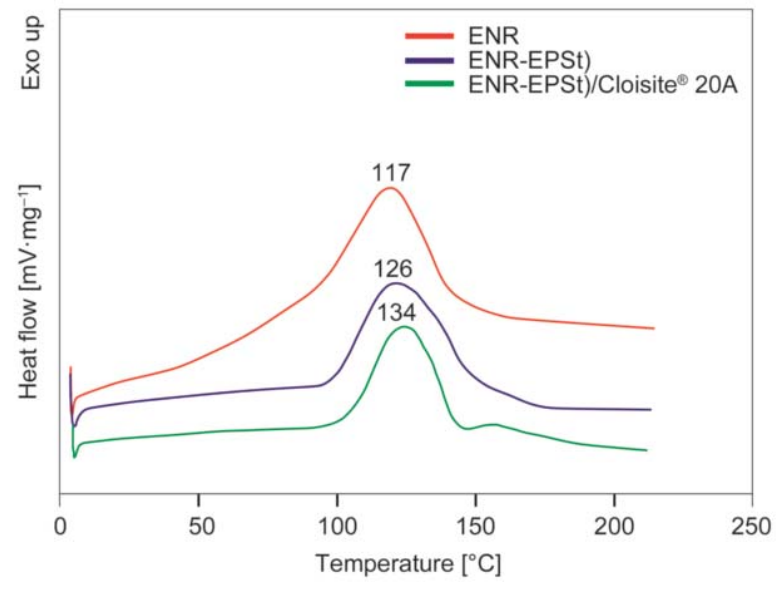

Figure 10. Dynamic DSC curves of ENR, ENR-EPSt, and ENR-EPSt/Cloisite ${ }^{\circledR}$ 20A nanocomposite.

The cure temperature of the ENR, ENR-EPSt, and ENR-EPSt/Cloisite ${ }^{\circledR}$ 20A nanocomposite were investigated using dynamic DSC approach as shown in Figure 10. As seen, the addition of EPSt as well as Cloisite ${ }^{\circledR} 20 \mathrm{~A}$ lead to a decrease in the heat of reaction. This phenomenon is primarily due to the decrease in rate of reaction with the addition of EPSt and clay, which lead to decrease in the cross-linking density. Despite, the intramolecular, intermolecular and van der Waals interactions between ENR and EPSt as well as strong electrostatic interactions (e.g., hydrogen bonding) between the functional groups of polymeric chains and Cloisite ${ }^{\circledR} 20$ A resulted to higher thermal stability according to the TGA results. In addition, the reducing cross-linking density is an effective way to afford modified novolac-based epoxy resins [25].

\section{Conclusions}

An efficient strategy for the fabrication of an epoxy resin nanocomposite based on novolac was designed and applied successfully. It was revealed that the incorporation of epoxylated polystyrene as well as a modified clay can improve the thermal stability of the ENR resin. The TEM and XRD analysis exhibited that the fabricated nanocomposite has an exfoliated structure. As the results, the fabricated C-ENREPSt/Cloisite ${ }^{\circledR} 20 \mathrm{~A}$ nanocomposite may be applied in various industrial fields including, electronic industries, molding compounds, adhesive, foundry, and coatings mainly due to its low production cost, and excellent thermal stability in comparison with neat ENR resin.

\section{Acknowledgements}

The authors gratefully acknowledge the partial financial support from Payame Noor University, Tehran, Iran, and Nano Drug Delivery Research Center, Kermanshah University of Medical Sciences, Kermanshah, Iran.

\section{References}

[1] Barzoki P. K., Rezadoust A. M., Latifi M.: Tunable effect of polyvinyl butyral nanofiber veil on fracture toughness of glass reinforced phenolic composites manufactured with out of autoclave method. Polymer Testing, 71, 255-261 (2018).

https://doi.org/10.1016/j.polymertesting.2018.08.034

[2] Ferdous W., Ngo T. D., Nguyen K. T. Q., Ghazlan A., Mendis P., Manalo A.: Effect of fire-retardant ceram powder on the properties of phenolic-based GFRP composites. Composites Part B: Engineering, 155, 414-424 (2018).

https://doi.org/10.1016/j.compositesb.2018.09.032

[3] Li Z., Li Y., Wan J., Zhao S.: Static and dynamic adhesive properties between continuous basalt fibre cords and NR/SBR matrix tackified by $p$-octylphenolic resins. International Journal of Adhesion and Adhesives, 85, 1-7 (2018).

https://doi.org/10.1016/j.ijadhadh.2018.05.015

[4] Ma C., Ma Z., Gao L., Liu Y., Wang J., Song M., Wang F., Hatsuo I.: Laser ablation behavior of nano-copper particle-filled phenolic matrix nanocomposite coatings. Composites Part B: Engineering, 155, 62-68 (2018). https://doi.org/10.1016/j.compositesb.2018.07.048

[5] Mousavi A., Roghani-Mamaqani H., Salami-Kalajahi M., Shahi S., Abdollahi A.: Grafting of silica nanoparticles at the surface of graphene for application in novolactype phenolic resin hybrid composites. Materials Chemistry and Physics, 216, 468-475 (2018).

https://doi.org/10.1016/j.matchemphys.2018.05.017

[6] Salaeh S., Cassagnau P., Boiteux G., Wießner S., Nakason C.: Thermoplastic vulcanizates based on poly(vinylidene fluoride)/epoxidized natural rubber blends: Effects of phenolic resin dosage and blend ratio. Materials Chemistry and Physics, 219, 222-232 (2018).

https://doi.org/10.1016/j.matchemphys.2018.08.029

[7] Wang B., Fu Q., Yin T., Li H., Qi L., Fu Y.: Grafting CNTs on carbon fabrics with enhanced mechanical and thermal properties for tribological applications of carbon fabrics/phenolic composites. Carbon, 139, 45-51 (2018).

https://doi.org/10.1016/j.carbon.2018.06.032

[8] Wang C., Zhang B-X., Luo Z., Zhang Y., Zhou H., Guo Y., Zhao T.: Preparation and properties of a novel addition-curable phenolic resin containing boron element. Polymers for Advanced Technologies, 29, 3014-3019 (2018).

https://doi.org/10.1002/pat.4421 
[9] Conejo L. S., Costa M. L., Oishi S. S., Botelho E. C.: Degradation behavior of carbon nanotubes/phenol-furfuryl alcohol multifunctional composites with aerospace application. Materials Research Express, 4, 105701/1-105701/16 (2017). https://doi.org/10.1088/2053-1591/aa8f60

[10] Yi T., Zhao S., Gao W., Guo C., Yang L., Du G.: The similar in-situ polymerization of nano cupric oxide preparation and phenol formaldehyde resin synthesis: The process and mechanism. International Journal of Adhesion and Adhesives, 87, 109-118 (2018).

https://doi.org/10.1016/j.ijadhadh.2018.10.003

[11] Abdollahi A., Roghani-Mamaqani H., Salami-Kalajahi M., Mousavi A., Razavi B., Shahi S.: Preparation of organic-inorganic hybrid nanocomposites from chemically modified epoxy and novolac resins and silica-attached carbon nanotubes by sol-gel process: Investigation of thermal degradation and stability. Progress in Organic Coatings, 117, 154-165 (2018).

https://doi.org/10.1016/j.porgcoat.2018.01.001

[12] Mousavi A., Roghani-Mamaqani H., Salami-Kalajahi M., Shahi S., Abdollahi A.: Modification of graphene with silica nanoparticles for use in hybrid network formation from epoxy, novolac, and epoxidized novolac resins by sol-gel method: Investigation of thermal properties. Express Polymer Letters, 12, 187-202 (2018). https://doi.org/10.3144/expresspolymlett.2018.18

[13] Abbasian M., Judi M., Mahmoodzadeh F., Jaymand M.: Synthesis and characterization of a $\mathrm{pH}$ - and glucose-responsive triblock copolymer via RAFT technique and its conjugation with gold nanoparticles for biomedical applications. Polymers for Advanced Technologies, 29, 3097-3105 (2018).

https://doi.org/10.1002/pat.4430

[14] Abbasian M., Ghaeminia H., Jaymand M.: A facile and efficient strategy for the functionalization of multiplewalled carbon nanotubes using well-defined polypropylene-grafted polystyrene. Applied Physics A: Materials Science and Processing, 124, 522/1-522/9 (2018) https://doi.org/10.1007/s00339-018-1943-4

[15] Mohammad-Rezaei R., Massoumi B., Abbasian M., Jaymand M.: Novel strategies for the synthesis of hydroxylated and carboxylated polystyrenes. Journal of Polymer Research, 25, 93/1-93/8 (2018). https://doi.org/10.1007/s10965-018-1490-x

[16] Karaj-Abad S. G., Abbasian M., Jaymand M.: Grafting of poly[(methyl methacrylate)-block-styrene] onto cellulose via nitroxide-mediated polymerization, and its polymer/clay nanocomposite. Carbohydrate Polymers, 152, 297-305 (2016).

https://doi.org/10.1016/j.carbpol.2016.07.017
[17] Hatamzadeh M., Jaymand M.: Synthesis of conductive polyaniline-modified polymers via a combination of nitroxide-mediated polymerization and 'click chemistry'. RSC Advances, 4, 28653-28663 (2014).

https://doi.org/10.1039/c4ra00864b

[18] Jaymand M.: Synthesis and characterization of well-defined poly (4-chloromethyl styrene-g-4-vinylpyridine)/ $\mathrm{TiO}_{2}$ nanocomposite via ATRP technique. Journal of Polymer Research, 18, 1617-1624 (2011). https://doi.org/10.1007/s10965-011-9566-x

[19] Abreu C. M. R., Fonseca A. C., Rocha N. M. P., Guthrie J. T., Serra A. C., Coelho J. F. J.: Poly(vinyl chloride): Current status and future perspectives via reversible deactivation radical polymerization methods. Progress in Polymer Science, 87, 34-69 (2018).

https://doi.org/10.1016/j.progpolymsci.2018.06.007

[20] Hatamzadeh M., Jaymand M., Massoumi B.: Graft copolymerization of thiophene onto polystyrene synthesized via nitroxide mediated polymerization and its polymer-clay nanocomposite. Polymer International, 63, 402-412 (2014). https://doi.org/10.1002/pi.4513

[21] Bunekar N., Tsai T-Y., Huang H-P.: Effect of functionalized graphene with modified clay on flammability of copper clad laminated novolac cured epoxy composites. Polymer-Plastics Technology and Engineering, in press (2018). https://doi.org/10.1080/03602559.2018.1493120

[22] Jaymand M.: Surface modification of montmorillonite with novel modifier and preparation of polystyrene/ montmorillonite nanocomposite by in situ radical polymerization. Journal of Polymer Research, 18, 957-963 (2011). https://doi.org/10.1007/s10965-010-9495-0

[23] Jaymand M.: Modified syndiotactic polystyrene/montmorillonite nanocomposite: Synthesis, characterization, and properties. Macromolecular Research, 19, 998-1005 (2011). https://doi.org/10.1007/s13233-011-1015-5

[24] Jaymand M.: Synthesis and characterization of novel type poly (4-chloromethyl styrene-grft-4-vinylpyridine) $/ \mathrm{TiO}_{2}$ nanocomposite via nitroxide-mediated radical polymerization. Polymer, 52, 4760-4769 (2011). https://doi.org/10.1016/j.polymer.2011.08.016

[25] Yu P., He H., Jiang C., Wang D., Jia Y., Zhou L., Jia D. M.: Reinforcing styrene butadiene rubber with ligninnovolac epoxy resin networks. Express Polymer Letters, 9, 36-48 (2015). https://doi.org/10.3144/expresspolymlett.2015.5 